\title{
Translation Strategies for Texts of Science and Technology
}

\author{
Wang Zheng \\ College English Department, Xiamen University Tan Kah Kee College, 363105 \\ 489406596@qq.com
}

Key Words: Translation; Strategies; Science; Technology

\begin{abstract}
We are living in an epoch in which science and technology are developing rapidly. Therefore, technical translation is playing an increasingly important part in the economic development and cultural prosperity of all nations. Newmark (1981:21) classifies different texts into three categories: expressive text, informative text, vocative text. Texts for science and technology belong to what we call a typical and distinctive informative type of texts. This paper explores the translation approaches and strategies applicable in texts of science and technology and then further explores the language, lexical and syntax features of texts for science and technology and discusses useful strategies for the translation of this type of text. In addition, a large number of sample translations of different types of technical texts, e.g. instructions, technical documents, etc. have been collected as data for discussions of the features and characteristics of typical technical texts. Finally, this thesis presents a number of methods and strategies for the translation of technical texts according to functional translation theory from a completely new perspective.
\end{abstract}

\section{Introduction}

Newmark (1981:21) classifies different texts into three categories: expressive text, informative text, vocative text. Texts for science and technology belong to what we call a typical and distinctive informative type of texts. The language of texts of science and technology is characterized by conciseness, accuracy, objectiveness, practicality, briefness and concreteness. It is therefore imperative that translators of this typology retain these characteristics when they reproduce them in the target language. Besides, the format of texts of science and technology is often standard, especially in technical texts. Even worse, a high proportion of such texts are poorly written and sometimes inaccurate, and it is usually the translator's job to "correct" their facts and their style. (Newmark, 1988: 41). Meanwhile, the author's status in the text is anonymous, which adds to the difficulty of translation.

Since proper translation of informative texts helps the learning of useful foreign technology and expertise worldwide and promotes China's technology development as a civilized country. There is no doubt that technical translation plays an extremely important role so further research should be made in order to enhance the translation quality of this typology.

\section{The Translation Criterion for Texts of Science and Technology}

In technical translation, the main function is to inform the reader about technical information and phenomena in the real world. The choice of linguistic and stylistic forms is subordinate to this function. In a translation where both the source and the target texts are of the informative type, the translator should attempt to give a correct and complete representation of the source text's content and should be guided, in terms of stylistic choices, by the dominant norms of the target language and culture"(Nord, 1997:37).

Therefore, the translation of content-focused informative texts should be guided by the strategy of domestication and its relevant approaches informed by tenets of functional translation theory.

Therefore, the first criterion is to ascertain whether their content and information is fully represented in the target language; Thus, once a given text is identified as belonging to the content-focused type, an important component of its translation method has been determined. Content-focused texts require invariance in transfer of their content. The primary task is to inform 
readers with certain scientific facts and content. The criterion of judging the success of these texts is whether facts and contents are made clear to readers. No ambiguity is allowed, for there is only one fact.

The second criterion for evaluating a content-focused text is the thoroughness of its orientation to the target language. Since a content-focused informative text is concerned with effective communication and accuracy of information and messages. That means expressing the same messages using the form of the target language as is shown in the following chart (figure 1). The content of source language should be transformed into target language content using target language forms. Therefore, content is more important than any other factors. Usually, for better understanding of texts for science and technology, translators change typically English grammar structure into Chinese structure, to better tell readers the fact that happens.
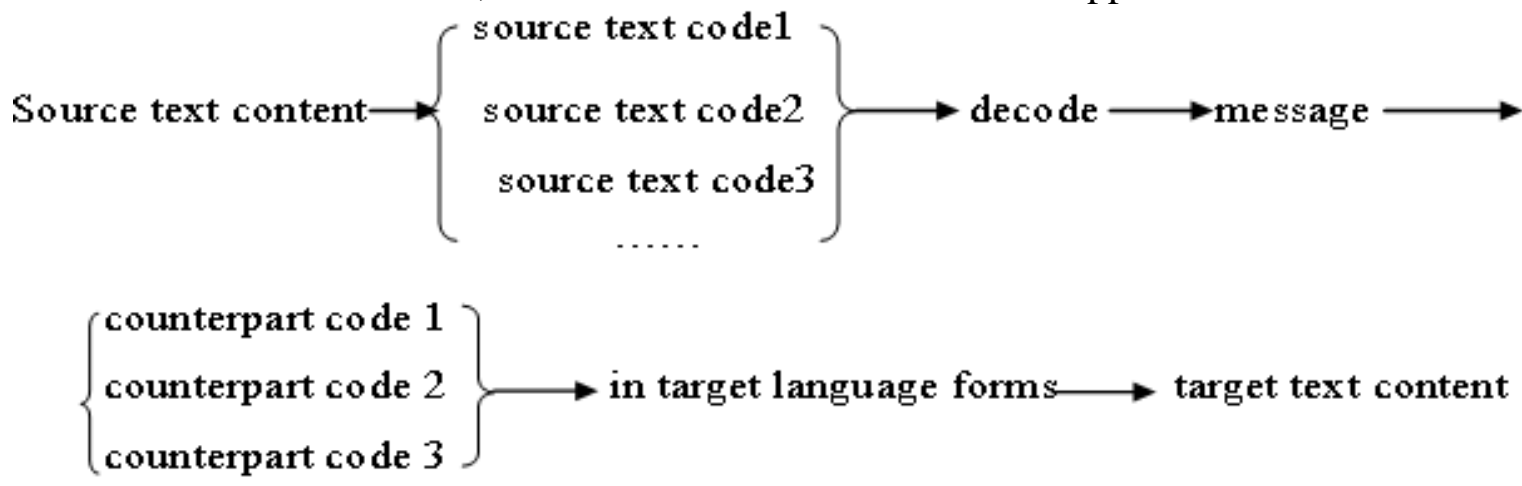

Figure1.Transformation process from source text to target text

\section{Translation Strategies of Texts for Science and Technology}

Based on the linguistic feature and translation criterion of technical texts analyzed above, this following part of this paper will explore several methods and strategies for the translation of technical texts according to functional translation theory from a completely new perspective.

Lexical Feature-Accuracy of Technical Terms. There are numerous professional terms in technical texts, and the texts are to convey scientific and technical content. So a translator must not only have a good command of language and translation competence, but know about science and technology. When translating, the translator must ensure the accuracy and trueness of the message in the translated text and carefully translate the technical terms so as to achieve the function of the translated text. To translate the terms specially used in certain fields, we must have some necessary knowledge of the relevant fields. For this purpose, a translator has to keep in touch with the technical professionals to make clear the specific meaning of a technical word and to avoid being the laughing stock. The technical words fall in three categories: terms specially used in one field, terms derived from general words or terms that can be used in many fields, with different meaning in different fields, and lastly, acronyms.

Terms Specially Used in one Field only. Terms in the first category seem to be difficult at the first sight because they are seldom used in general writings and require special knowledge for correct understanding. In fact, these words are easier to grasp for they seldom have ambiguous meaning in other fields. Once you look up the professional dictionaries, you will never make mistakes. For example:

matrass 卵形瓶

litmus 石荵

reagent 试剂

photo-chemistry 光电化学

cochlear [解剖]耳蜗

abreaction:(心理学)消散

(情感, 情绪等的)发泄 


\section{Photopolymer 光聚合版}

ST: New HSR and Maglev would have all-new, state-of-the-art train control systems. The Accelerail options were estimate with train control systems providing speed and authority enforcement.

TT: 新型高速列车或磁浮列车须配置全新的、造型精美的列车操纵系统, 可供选用的列车 操纵系统必须能提供高速和强大的加速力。(Yang Shoukang, 2003:109)

Terms Derived From General Words Or Terms. (that can be used in many fields, with different meaning in different field)

To understand the terms in this class, we have to pay attention to the context, to make clear which field we are dealing with. Translators have to differentiate their exact meaning in different contexts.

e.g. throughput 生产能力, (计算机网络)吞吐量

latency 等待时间, 延时

carrier 电信公司, 载波

forwarding technology 转发技术

header (数据)包头

variable star 变星 variable (数)变量

magnitude 大小, 量级, 星等(天文)

test tube 试管

Here are more examples to show that in different contexts, the words have the different meanings.

Any network element that acts as an intermediary system for data transfer, such as a router or a firewall, has two main responsibilities. (from the product description of a router/firewall manufacturer)

任何充当数据传输中介系统的网络部件, 比如路由器和防火墙, 都有两个重要功能:

Usually, element can be translated as “因素或要素” in general texts. In technical field, it is usually translated as “元件”. But “元件”is often associated with resistors, capacitors ,and the like. However, “部件” can be either a big device or a small one. Here, obviously, routers and firewalls are not small devices, and can not be referred to as “元件”, so we say “部件”.

However, in chemistry, “element” is translated into”元素”.

氮族元素 nitrogen group elements

Acronyms. The most important method for grasping the meaning of acronyms is to accumulate when reading. When you are familiar enough with many acronyms, it will be possible for you to guess the meaning.

IAPO: International Association of Physical Oceanography 国际物理海洋学协会

ISCERG: International Society for Clinical Electroretinography 国际临床视网膜电检法学会

Acronyms in computer network:

ISDN: integrated service digital network 综合服务数字网

DNS: domain name system 域名系统

FTP: file transfer protocol 文件传输协议

HTTP: hyper-text transmission protocol 超文本传输协议

HTML: hyper-text mark-up language 超文本标识语言

To accurately translate these terms, it is always suggested that a translator should ask for advice from a specialist in this relevant technical field or resort to technical or specialized documents, dictionaries or materials.

\section{Syntactic Feature Of Texts Of Science And Technology}

Transformation Of Nominal Forms. Differences in the logic of thinking in English and Chinese have led to the differences in the use of words. We have seen that in English nouns dominate and in Chinese, verbs outweigh. Especially in technical English writing, nouns are used very often and 
the nominalization of verbs is common. In translation, sometimes it is necessary to transform the parts of the words and to make them suit the Chinese logic better, that is to say, the abstract nominal forms are changed into concrete ones. In translating such items, translators may shift the part of speech of a noun into a verb, adjective to accommodate to Chinese reading habits.

$\mathrm{ST}$ : Whisky of 90 proof is $45 \%$ alcohol.

TT: 90 度的威士忌含酒精 45\% (Lu Gusun, 1993:145)

ST: An improvement of its performance can be effected by the use of super-heated steam.(Li Bingwu 2002:5)

TT: 可以使用超热蒸气改进其性能。

ST: Television is the transmission and reception of images of moving objects by radio waves.(Li Bingwu 2002:5)

TT: 电视通过无线电波发射和接收活动物体的图像。

Some nominal forms can also be transformed into adjectives in translation

ST: Contamination-proof is an absolute necessity in the maintenance of fluidic devices.

TT: 防止污染对保养射流装置是绝对必要的。 (Wu Baoliang 1995:111)

From Passive Voice To Active Voice. In scientific and technological field, facts, methods and rules of nature are valued. Therefore, scientific documents try to appear as objective as possible and no personal mood should be involved. However, in the Chinese way of expression, passive voice is not very commonly used. In the translation of the following sentence, the Chinese text tries to avoid using “被” in translating. Active voice is usually used in Chinese texts instead.

ST: If an oscillatory motion was superimposed on steady shearing, the maximum torque on the top plate during the combined motion was scarcely more than the torque in steady shearing alone; the minimum was considerably less.

$\mathrm{TT}$ : 如果往稳恒剪切上叠加振荡运动, 则在联合运动过程中作用于顶板上的最 大转矩很少 大于仅稳恒剪切时的转矩, 而最小转矩则比后者小得多。(Yan Qingjia; Yan Wenpei,1992:7)

ST: The crater may have been caused by an asteroid crashing into the earth some time during the Cretaceous period 65 million years ago.

TT: 这个断裂口可能是 6500 年前白严纪时期一颗小行星撞击地球形成的。(Tan Weiguo, 2005: 213)

ST: The problems involved primarily the oceans and atmosphere --- the commons which are shared by all and are the basis of our life-support system.

$\mathrm{TT}$ : 这些问题主要涉及海洋和大气层, 而海洋和大气层是人类所共有的, 是维持生命的基 础 (Tan Weiguo, 2005: 215)

ST: 金属热处理常用煤气炉, 油炉和电炉。

TT: Gas, oil and electric furnaces are commonly used for heat treating metals.

Restructuring The Syntax. There is often much content with long sentences and complex structures in technical Texts. A translator has to divide long sentences into short ones, make complex structures simplified, or sometimes adjust the order of the content. In such cases, translators may not necessarily literally follow the natural structure of the English sentence; instead, they may break the sentence into parts, or even rearrange its components, restructure the whole sentence to ensure better understanding.

ST: Correct timing is of the utmost importance, and also extreme accuracy, down to a twenty-thousandth part of an inch, in the grinding of certain parts of the fuel injecting pump and the valves.

TT: 校正定时的工作极其重要, 而准确的精密度也是及其重要的, 对喷油洜与气阀某些部件 的研究, 密度可达到两万分之一英寸。(Lu Min, 2005: 129)

ST:对于飞机自动防故障装置的设计, 只要其结构部件疲劳状态不至于危及飞机安全、缩短 飞行寿命或因维修过多导致使用率和经济效益降低, 那么, 一般的部件疲劳是可以承受的。

TT: Fatigue failure of structural components of an aircraft of fail-safe design is quite acceptable, providing it does not occur often enough to endanger the aircraft, reduce its service life, or reduce 
its utilization and economy by excessive maintenance.

ST: Wind tunnel and other research simulating a wide range of track conditions Convinced DB that in most weather conditions, no difficulties would be experienced in running an ICE2 on NBS track at up to the designed top speed of $280 \mathrm{~km} / \mathrm{h}$, with its aerodynamically-shaped driving trailer leading.

TT: 模拟各种不同路轨条件的风洞和其他实验使德国联邦铁路局深信，在大部分气候条件 下, 在 NBS 线路上, 配有动力挂车做前导的流线型 ICE2 型城际快车, 以每小时高达 280 公 里的最高设计时速行驶不会有任何困难。(Lu Min, 2005:121)

\section{Conclusion}

Unlike literary works, the beauty of language in scientific texts gives way to content. Once facts are misunderstood, the result could be disastrous. "Technical translation, ranging from brief abstracts through summaries, is to complete reproduction of content without form” (Newmark, 2001:12). In other words, the focus of texts of science and technology translation is on the transfer of message or information. So the truth conveyed by the information is the core of this type of text. Therefore, Newmark (1988:39) suggests adopting the approach of communicative translation, with the attempt to produce the effect to the target readers as close as possible to that obtained by the original readers, emphasizing the accuracy and truth of the process in information transmission. For the limited pages in the thesis, the author cannot explore the translation strategies in details. Those who show interest in technical translation studies can refer to functional translation theory and make more translation practice to probe into more effective strategies and approaches to pragmatic translation.

\section{Reference:}

[1] Newmark, P. Approaches to Translation [M]. Oxford: Pergamon. 1981.

[2] Newmark, P. A Textbook of Translation [M]. New York: Prentice Hall International, 1988.

[3] Newmark, P. (2006). About Translation [M]. Beijing: Foreign Language Teaching and Research Press.

[4] Nord, C. A Functional Typology of Translation [M]. Amsterdam, 1997.

[5] Lu Min. English Translation Practice[M]. Beijing: Foreign Language Press, 2005

[6] Tan Weiguo. A New Textbook in Translation Between English and Chinese [M].Shanghai: East China University of Science and Technology Press, 2005.

[7] Yan Qingjia, Yan Wenpei. Method of Technical English Translation [M]. Beijing: Metallurgical Industry Press, 1992.

[8] Wu Baoliang. Understanding and Translation of Noun Phrases in Technical English[J]. Journal of Northwest University of Light Industry, 1995(3): 111-112.

[9] Yang Shoukang. On Translation of Technical English and Technical Translation[M]. Hefei: Anhui Literature and Art Publishing House, 2003:24-25. 